\title{
Anesthesia Probe
}

National Cancer Institute

\section{Source}

National Cancer Institute. Anesthesia Probe. NCI Thesaurus. Code C126768.

An ultrasound probe suitable for use during an anesthesia procedure to facilitate the placement of local or regional anesthetics. 